\title{
A Novel Multi-signaling Optical-electrochemical Chemosensor for Anions Based on Tetrathiafulvalene
}

\author{
Haiyan Lu, Wei Xu*, Deqing Zhang, Chuanfeng Chen, Daoben Zhu*
}

\section{Supporting Information}

1. Synthetic Experimental

2. Fluorescent spectra study:

3. CV Study

4. UV study: 


\section{Synthetic Experimental}

Receptor 1: compound $2(0.077 \mathrm{~g}, 0.182 \mathrm{mmol})$ was dissolved in dry $\mathrm{CH}_{2} \mathrm{Cl}_{2}$, then a solution of $3(0.164 \mathrm{~g}, 0.456 \mathrm{mmol})$ in dry THF $(15 \mathrm{ml})$ containing $\mathrm{NEt}_{3}(1 \mathrm{~mL})$ was added dropwise. Within a few minutes the solution became clear and a red precipitate appeared. The reaction mixture was allowed to stir at room temperature overnight, and then it was heated at $60^{\circ} \mathrm{C}$ for $48 \mathrm{hr}$. After complete evaporation of the solvent, the resulting residue was dissolved in $\mathrm{CHCl}_{3}$ and washed once with an aqueous $\mathrm{NaOH}$ solution $\left(10^{-2} \mathrm{M}, 40 \mathrm{ml}\right)$ and twice with water, the $\mathrm{CHCl}_{3}$ extracts were concertrated in vacuo to give a residue that was subjected to column chromatography (silica gel, 5:1 $\left.\mathrm{CHCl}_{3}: \mathrm{CH}_{3} \mathrm{OH}\right)$ to afford the compound $1(0.065 \mathrm{~g}, 33.5 \%) .{ }^{1} \mathrm{H}$ NMR (DMSO-d $\left.\mathrm{d}_{6}\right): \delta$ $10.06(\mathrm{~s}, 1 \mathrm{H}), 8.89(\mathrm{~s}, 1 \mathrm{H}), 8.38$ (d, J=8.5 Hz, 2H), 8.35 (t, J=5.1 Hz, 2H, NH), 8.23 $(\mathrm{d}, J=7.04,2 \mathrm{H}), 7.87(\mathrm{t}, J=5.6 \mathrm{~Hz}, 2 \mathrm{H}, \mathrm{NH}), 7.68(\mathrm{t}, J=7.8 \mathrm{~Hz}, 2 \mathrm{H}), 7.27(\mathrm{~s}, 2 \mathrm{H}$, $\mathrm{C}=\mathrm{CH}), 3.19(\mathrm{t}, J=5.4 \mathrm{~Hz}, 4 \mathrm{H}), 3.12(\mathrm{t}, J=5.4 \mathrm{~Hz}, 4 \mathrm{H}), 2.44(\mathrm{~s}, 6 \mathrm{H}) .{ }^{13} \mathrm{C} \mathrm{NMR}$ (DMSO-d $\left.{ }_{6}\right): \delta 159.2,136.5,134.5,133.6,132.1,130.1,129.7,127.2,126.7,126.3$, 125.0, 124.9, 122.2, 114.1, 105.9, 79.6, 42.2, 18.9. HRMS (FAB) (m/z): Calcd. for $\mathrm{C}_{36} \mathrm{H}_{34} \mathrm{~N}_{4} \mathrm{O}_{6} \mathrm{~S}_{14}, 1065.8562$; found:1065.8588.

2. Fluorescent spectra study: 


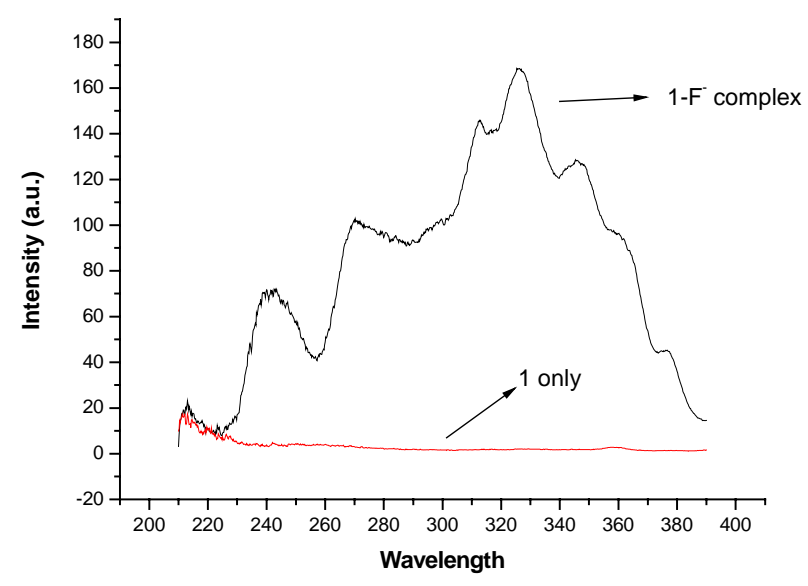

Figure 1. Fluorescence excitation spectrum of $1-\mathrm{F}^{-}$complex
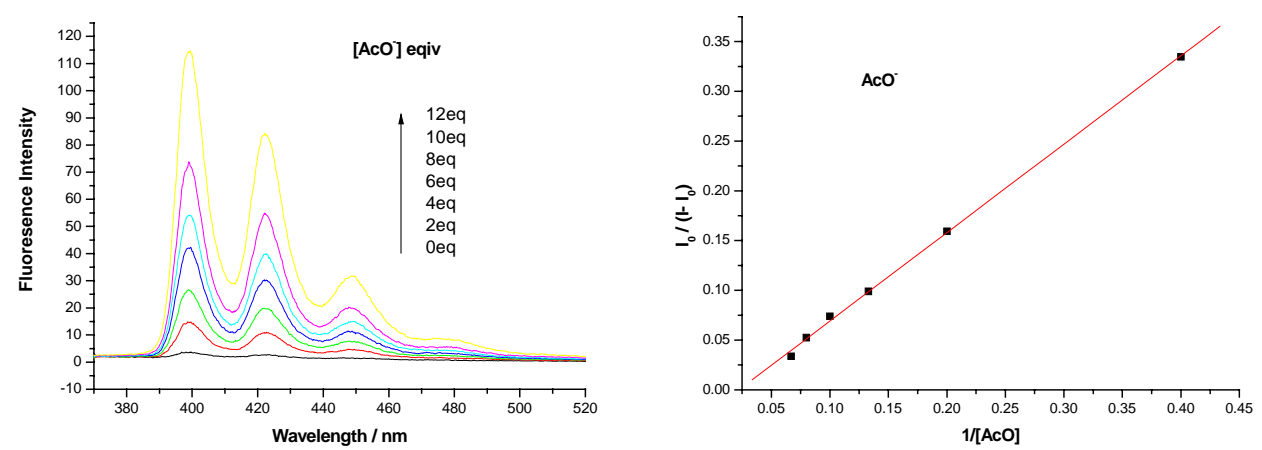

Figure 2. Changes in fluorescence emission for receptor $\mathbf{1}\left(1.25 \times 10^{-5} \mathrm{M}\right)$ upon addition of $\mathrm{AcO}^{-}$in $\mathrm{CH}_{2} \mathrm{Cl}_{2}, \lambda \mathrm{ex}=325 \mathrm{~nm}, \mathrm{Ka}=2.22 \times 10^{3} \mathrm{M}^{-1}(\mathrm{R}>0.999)$
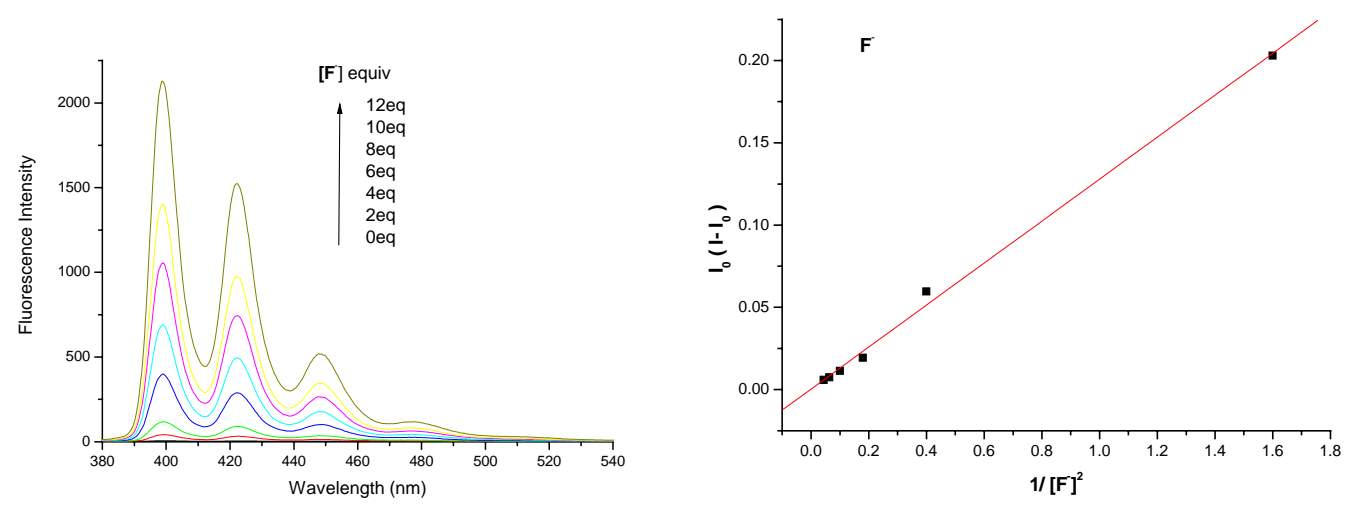

Figure 3. Changes in fluorescence emission for receptor $\mathbf{1}\left(1.25 \times 10^{-5} \mathrm{M}\right)$ upon addition of $\mathrm{F}^{-}$in $\mathrm{CH}_{2} \mathrm{Cl}_{2}, \lambda \mathrm{ex}=325 \mathrm{~nm}, \mathrm{Ka}=1.51 \times 10^{8} \mathrm{M}^{-2}(\mathrm{R}>0.999)$. 

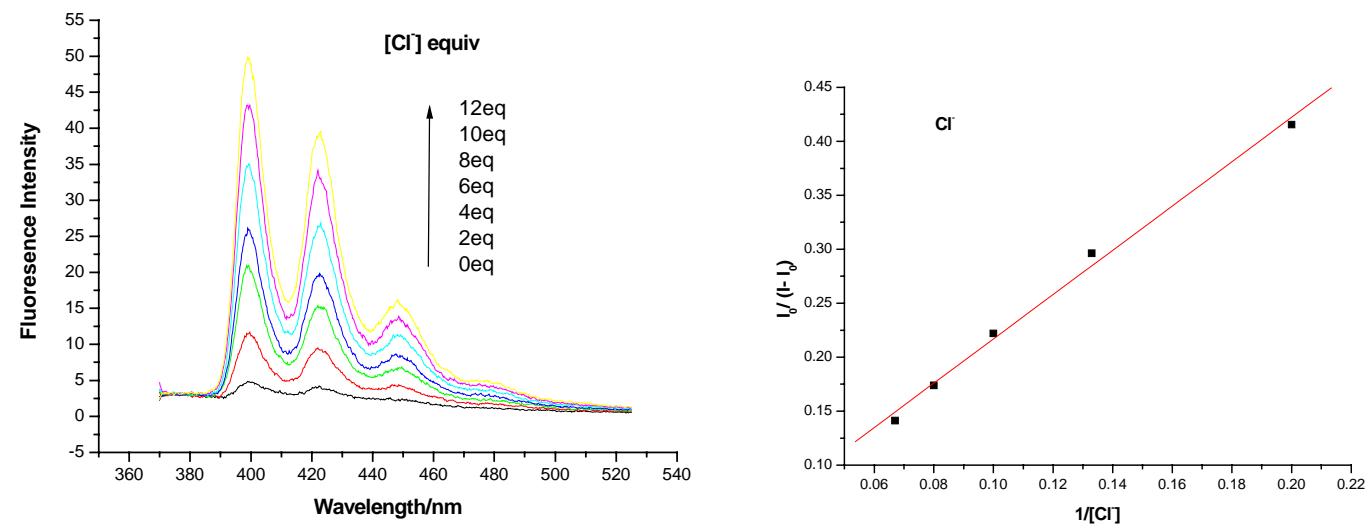

Figure 4. Changes in fluorescence emission for receptor $\mathbf{1}\left(1.25 \times 10^{-5} \mathrm{M}\right)$ upon addition of $\mathrm{Cl}^{-}$in $\mathrm{CH}_{2} \mathrm{Cl}_{2}, \lambda e x=325 \mathrm{~nm}, \mathrm{Ka}=4.77 \times 10^{2} \mathrm{M}^{-1}(\mathrm{R}>0.999)$.
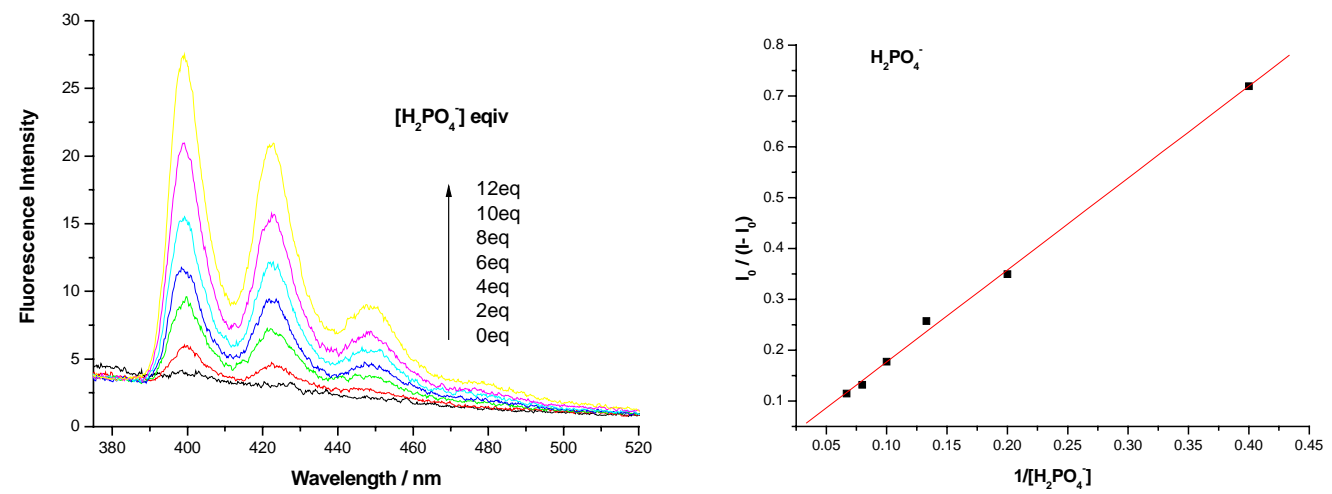

Figure 5. Changes in fluorescence emission for receptor $1\left(1.25 \times 10^{-5} \mathrm{M}\right)$ upon addition of $\mathrm{H}_{2} \mathrm{PO}_{4}^{-}$in $\mathrm{CH}_{2} \mathrm{Cl}_{2}, \lambda \mathrm{ex}=325 \mathrm{~nm}, \mathrm{Ka}=5.67 \times 10^{2} \mathrm{M}^{-1}(\mathrm{R}>0.997)$.

3. CV Study
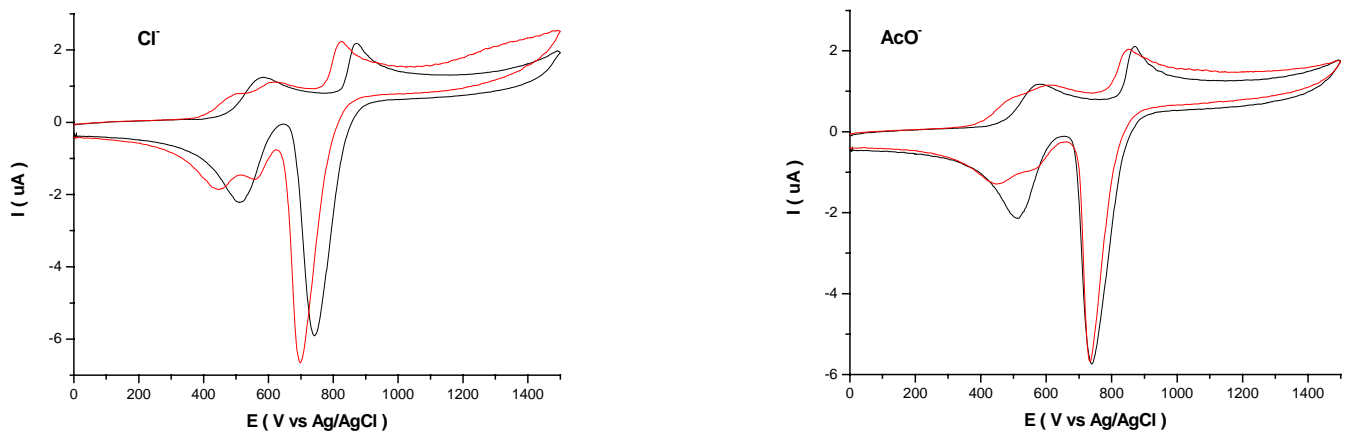

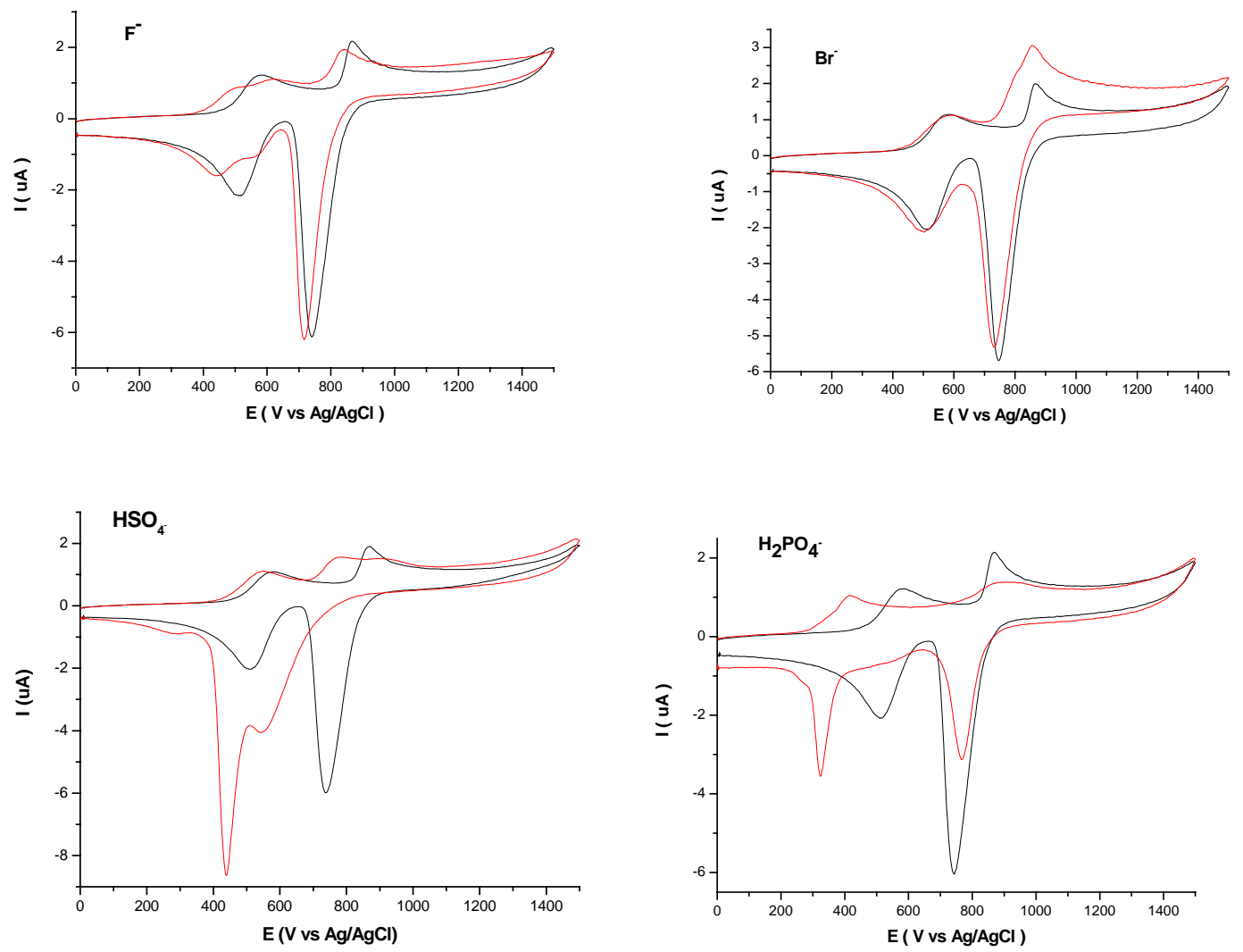

Figure 6. Cyclic voltammograms of $1\left(1.25 \times 10^{-4} \mathrm{M}\right)$ recorded in $\mathrm{CH}_{2} \mathrm{Cl}_{2}$ and $\mathrm{Bu}_{4} \mathrm{NClO}_{4}(0.1 \mathrm{M})$ as the supporting electrolyte in the presence of 2 equiv of anions.

4. UV study:

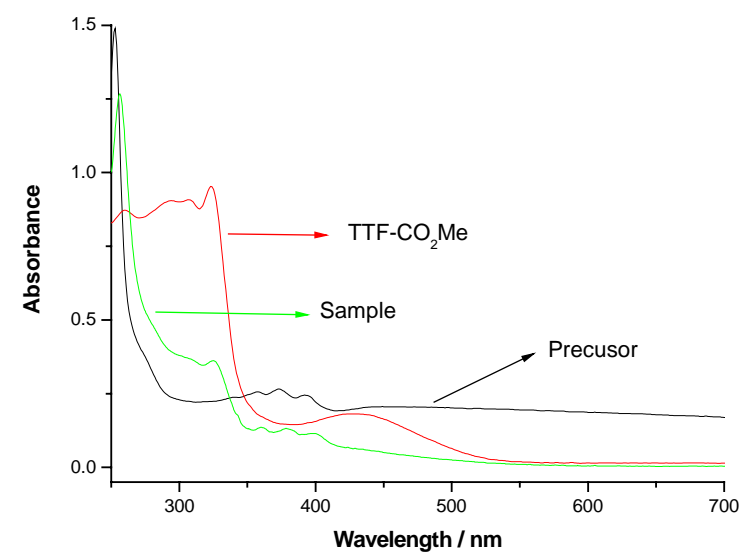




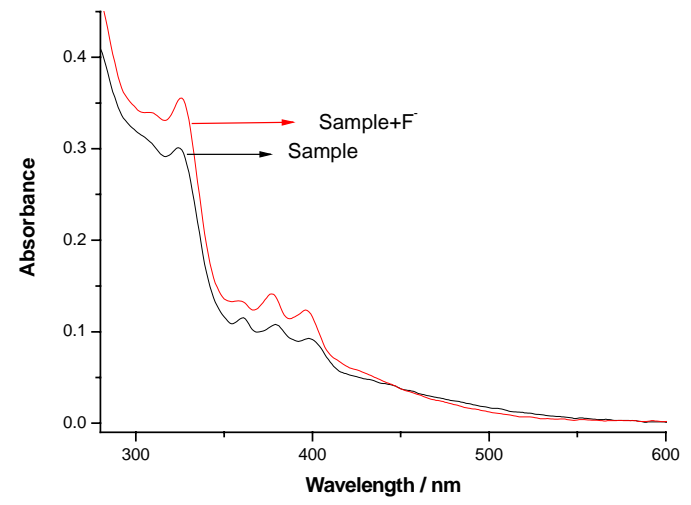

